\title{
Meninos órfãos vindos do Reino para a América Portuguesa: mestiçagem cultural
}

\section{Niños huérfanos procedentes del Reino a la América portuguesa: el mestizaje cultural}

https://doi.org/10.34112/2317-0972a2016v34n66p125-139

\section{Paulo Romualdo Hernandes ${ }^{1}$}

RESUMO: Este artigo analisa cartas jesuíticas que descrevem a vinda de meninos órfãos do Reino português, do Colégio dos Órfãos de Lisboa, para a América Portuguesa, para o Colégio dos Meninos de Jesus, de Salvador, e acompanha a narrativa dos padres sobre a peregrinação dos meninos pelas matas, pelas aldeias, pelos aldeamentos. Apresenta-se também o encanto e, por vezes, o desencanto no relato dos missivistas sobre a ação dos meninos órfãos com os habitantes das selvas e sua cultura. As cartas revelam, nas descrições da ação junto aos nativos, possíveis encontros e desencontros de culturas e algumas misturas que estão nas bases da formação da cultura brasileira.

Palavras-chave: América Portuguesa; século XVI; meninos órfãos.

RESUMEN: Este artículo analiza las cartas jesuitas que describen la llegada de los niños huérfanos del reino portugués, del Colégio de Órfãos de Lisboa, a América portuguesa, al Colégio dos Meninos de Jesus, de Salvador, y sigue el relato de los curas a respecto de la peregrinación de los niños por las florestas, los pueblos y las aldeas. También muestra el encanto y, a veces, la desilusión de los escritores sobre la acción de los niños huérfanos con los habitantes de la selva y su cultura. Las cartas revelan en las descripciones de la acción

1. Universidade Federal de Alfenas, Alfenas, MG, Brasil. 
con los nativos, posibles encuentros, choques culturales y algunas mezclas que están en la base de la formación de la cultura brasileña.

Palabras clave: Portugués América; siglo XVI; los niños huérfanos.

\section{INTRODUÇÃO}

Neste artigo apresenta-se a análise de algumas cartas que descrevem a vinda de meninos órfãos de Portugal para o Brasil e os encontros e desencontros entre culturas no contato dos meninos com a vida e os habitantes da selva. Esses encontros e desencontros descritos em cartas mostram o nascimento de uma nova cultura, misturada: a cultura brasileira, como síntese. Os meninos órfãos vindos do Reino tiveram importante missão em terras dos brasis, pois, além de serem educados pelos padres no "serviço divino", foram seus colaboradores. Em carta de 1552 (LEITE, 1954a, p. 374), Nóbrega conta que os meninos costumavam cantar, "pelo mesmo tom dos índios e com seus instromentos", cantigas na língua em louvor de Nosso Senhor, com que muito se abriam os corações dos índios.

$\mathrm{O}$ resgate desses acontecimentos - a vinda dos meninos órfãos; o encontro deles com os padres, com os meninos índios, com os meninos mestiços; a origem do Colégio dos Meninos de Jesus; o trabalho desses meninos com os homens do Novo Mundo; e o hibridismo causado por essa ação, entre outros fios dessa teia, no Brasil quinhentista - é importante para compreendermos a fundação não só da religiosidade brasileira, mas também da relação dos meninos com a educação, sujeitos fundamentais para a evangelização, para a missão da Companhia de Jesus (BITTAR, 2006).

\section{Os meninos e o Colégio dos Meninos de Jesus}

Dom João III, que havia recebido de volta a capitania da Bahia em fins de 1546, quando o capitão Francisco Pereira Coutinho foi morto pelos índios, fundou, em 1548, no arraial do Pereira, a cidade do Salvador, para ser sede do Governo Geral, instalado em 1549. Seu primeiro Governador, chefe do poder executivo, foi Tomé de Souza; o Ouvidor-Mor, autoridade judiciária, Pero Borges; e Provedor-Mor, administrador da fazenda, Antônio Cardoso de Barros (LEITE, 1954a, p. 4).

$\mathrm{O}$ regimento do governador geral, com as diretrizes principais do governo a ser iniciado, estabelecia como primeiro plano político que a principal tarefa no Brasil 
seria "o serviço de Deus e exalçamento da nossa santa fé" (LEITE, 1954a, p. 5). Para tal, deveriam ser seguidos alguns preceitos: primeiro a catequese, "porque a principal cousa que me moveu a mandar povoar as ditas terras do Brasil, foi pera que a gente delas se convertesse à nossa santa fé católica" (p. 5); depois, o aldeamento, separar os gentios que se tornassem cristãos dos outros que não o fossem, pois seria muito "inconveniente morarem na povoação dos outros e andarem misturados com eles" (p. 6) e seria melhor que os que se tornassem cristãos fossem morar próximos da capitania. E Dom João demonstrou preocupação com o ensino dos meninos, "porque neles se imprimirá melhor a doutrina, trabalhareis por dar ordem como se façam cristãos e que sejam ensinados e tirados da conversação dos gentios” (p. 6). Para a missão do serviço de Deus, de exaltar e converter todos à santa fé e de ensinar os meninos, foram designados, pelo monarca português, os homens da Companhia de Jesus, cujo líder seria o padre Manuel da Nóbrega.

Líder da missão que veio ao Brasil com a determinação do Rei Dom João III de dar execução prática ao que consta das diretrizes principais do Governo Geral, Manuel da Nóbrega demonstraria inquietação em cumprir as tarefas que lhe foram designadas, principalmente a de ensinar os meninos. Na carta de 9 de agosto (LEITE, 1954a, p. 125) para o padre Simão Rodrigues, ele relataria sobre seu trabalho para escolher o lugar em que seria o Colégio, a escola de ler e escrever: ao lado de uma aldeia, da casa onde já estavam os jesuítas, que ficava próxima aos cristãos velhos e novos, mas tinha o inconveniente, segundo o governador Tomé de Souza, de ficar longe da cidade, o que era temível por causa das guerras com os gentios. No entanto, Nóbrega conta, nessa carta, que não acreditava que os gentios fariam mal aos padres, pela afeição que por eles já sentiam e porque, também, os que "am-d'estar no Collegio am-de ser filhos dos gentio" (p. 125). Errou: foi pregar na aldeia próxima da cidade, tentou demover os índios daquele que era o principal atributo dos homens na cultura nativa - matar os inimigos para vingar os parentes e devorá-los, a antropofagia - e teve de ser resgatado pelo governador e seus homens. Por fim, o governador colocou os homens da Companhia de Jesus próximos aos muros da cidade - aliás, em um casebre de taipa e barro espremido nos muros da cidade - e lá se dava início à casa de ler e escrever para os meninos índios e mestiços, órfãos ou não.

A dificuldade seria construir o colégio, embora Nóbrega (1988, p. 84) afirmasse: "a mantença dos estudantes, ainda que sejam 200, é muito pouca". Na carta de 1550, nos informes gerais sobre o Brasil e sobre os trabalhos da Companhia, Nóbrega 
(1988, p. 111) diz que espera a resposta para a construção do Colégio de Salvador, Bahia, pois que "os estudantes com pouco se manterão". Davam-se, assim, as bases para a construção do Colégio dos Meninos de Jesus, futuro Colégio de Jesus. Era uma construção de taipa e barro, que durava pouco, sendo reconstruída a cada três anos. Em 1551, Nóbrega (1988), em carta a Dom João III, fala sobre o "Collégio" da Bahia que já estava bem principiado, que havia nele 20 meninos pouco mais ou menos, e pede para que o Governador faça casa para eles, pois as que havia eram feitas "por nossas mãos e são de pouca duração" (LEITE, 1954a, p. 126).

Em 1550, juntamente com a segunda leva de padres e irmãos da Companhia de Jesus, vieram de Lisboa sete ou oito meninos órfãos, dos quais quatro foram os primeiros do Colégio dos Órfãos de Lisboa, idealizado por Pedro Domenech e fundado com a participação da Família Real no dia da inauguração, em agosto de 1549 (LEITE, 1954a, p. 25). O Colégio tinha a função principal de tirar os meninos órfãos das ruas e guiá-los nos caminhos da fé e do bem cristão e retirá-los da "perambulação" (FAVACHO, 2008, p. 656). Conta Domenech (LEITE, 1954a, p. 25) que quis "Nosso Senhor Jesus Cristo escolher destes órfãos sete pera irem pregar o seu sanctissimo nome aos gentios e infiéis, e coube a sorte a quatro deles, que foram dos primeiros que se tirarão da Ribeira [...]”. Vieram para servir a Deus e ajudar na pregação. Conta Pedro Domenech sobre o dia de partida dos meninos para a cidade do Salvador que, depois de jantar, se ajoelharam diante de uma imagem de Nossa Senhora e, com muitas lágrimas, despediram-se de outros irmãos órfãos que ficavam. "E acompanhados de todos os outros irmãos órfãos andaram em procissão cantando uma cantiga que diz: Grande Senhor nos é nascido humano e mais divino." (LEITE, 1954a, p. 172).

Os meninos, segundo o que descreve o padre, seguiram a pé em procissão pelas ruas de Lisboa até Belém, cantando Salve Rainha e umas prosas a Nossa Senhora. Eram seguidos por muitos fiéis e guiados pelos fogos que os moradores colocavam às janelas de suas casas, vendo aquele séquito passar. Chegaram a Belém para embarcar, pediram perdão pelos pecados ao padre Domenech e, então, abraçando-se uns aos outros com muito choro e devoção, ouviam daqueles que ficavam: "ó irmãos nossos, como nos deixais”. Então,

um dos órfãos, Francisco Carneiro, saltou no batel e arrimado à borda dele tomou a cruz na mão e, levantada no ar com grande fervor, começou a cantar a alta voz:

"Os mandamentos de Deus

Que havemos de guardar 
Dados pelo Rei dos céus

Para todos nos salvar” (LEITE, 1954a, p. 172).

Era tudo tão "fervente" que parecia ao padre Domenech que aqueles meninos seguiriam para o "martírio". Não deveria ser nada fácil a vinda dos meninos órfãos para um lugar desconhecido, ainda selvagem, com habitantes antropófagos. É preciso notar que os padres escreviam cartas com várias motivações, entre elas a remessa de informações sobre acontecimentos importantes, como essa do envio dos meninos órfãos que foram educados no Colégio dos Órfãos de Lisboa, criado por Domenech. Entre as motivações dos padres para escrever estava o intuito de reforçar a virtude dos missionários espalhados pelos diversos lugares em que se situava a Companhia de Jesus. As cartas eram lidas em voz alta, o que levava os ouvintes às lágrimas, ao tomarem conhecimento do destino de outros combatentes de Cristo - nesse caso, os meninos órfãos que seguiam para a América como mártires. As cartas circulavam, também, nas mãos dos principais da Companhia, que as divulgavam para a elite europeia, que assim ficava sabendo dos trabalhos dos padres pelo mundo (HANSEN, 2005) e, em razão da sua fé cristã, ajudava nas obras da Companhia, em busca de salvação.

Antes de atravessarmos o Atlântico com os pequenos mártires é preciso relatar certa dificuldade que enfrentavam em Portugal e que enfrentariam na América Portuguesa. Segundo Marcílio (2006), a Idade Moderna nasceu com a centralização institucional dos cuidados com o menor abandonado, quando surgiram os Hospitais e Misericórdias com esse fim. A Coroa, no entanto, não se responsabilizava pela manutenção desses estabelecimentos; quando muito, dava algum aporte financeiro. Desse modo, o Colégio dos Órfãos de Lisboa, para manter os meninos, devia receber ajuda financeira de outras fontes que não por dotação régia, como era o caso dos Colégios Canônicos. Embora a Coroa não se responsabilizasse pelo suporte financeiro para esses estabelecimentos, pois cuidar dos desvalidos era tarefa de todo bom cristão, preocupava-se com o atendimento e a manutenção desses novos estabelecimentos. Em 1514, foi publicado o Regimento das Capelas e Hospitais, com o intuito de "padronizar esses estabelecimentos e as formas de sua manutenção” (MARCÍLIO, 2006, p. 94). Por outro lado, as Ordenações Manuelinas (1521) responsabilizaram a municipalidade, em todo o Reino, pelo cuidado aos enjeitados. Ela devia arcar com a manutenção desses estabelecimentos com verbas de sua própria renda ou poderia criar uma taxa, a Finta dos Enjeitados, para tal fim. Aí residia, 
para o Colégio dos Meninos Órfãos de Lisboa, um problema com a municipalidade e com os munícipes, que certamente não desejavam um novo Colégio para manter. Talvez por esse motivo a Companhia de Jesus não tenha assumido para si a tarefa de cuidar de meninos órfãos. O Colégio do padre Domenech foi "fechado" por Loyola, em 1555, pois a Constituição da Companhia de Jesus rezava que os jesuítas não poderiam ter rendas que não fossem para a formação de quadros (CONSTITUIÇÕES, 1997), ou seja, para os Colégios Canônicos. Os jesuítas teriam problemas também com o Bispo e com a municipalidade para a manutenção do Colégio dos Meninos de Jesus de Salvador, lugar que recebera os meninos que embarcaram para Salvador, em 1550. Esse colégio foi transformado em Colégio Canônico, o Colégio de Jesus, sendo os meninos órfãos mais uma vez abandonados, agora pelos padres superiores da Companhia. Manuel da Nóbrega, no entanto, não os abandonou e alojou-os em casas próximas ao Colégio ou com pessoas de "bem".

Partindo de Lisboa rumo à cidade do Salvador, na Bahia, no Novo Mundo, seguiu a segunda leva de missionários jesuítas que vieram para a América Portuguesa com os meninos órfãos. Cruzaram o Atlântico em travessia que deveria ser difícil para os meninos, pois eram os "miúdos que mais sofriam com o difícil dia a dia em alto mar" (RAMOS, 2008, p. 19). Tinham de enfrentar fome, "abusos sexuais de marujos rudes e violentos" (RAMOS, 2008, p. 19), doenças - sobretudo pela forte exposição ao sal e ao sol -, naufrágios, entre outros perigos. Martírio que não amainaria em terra firme, pois o paraíso terrestre não permitia vida fácil a ninguém: a mata com seus perigos, a falta de alimentos e vestimentas, os nativos habituados às matas, que tinham na caça, incluindo humanos, sua principal forma de subsistência (HERNANDES, 2010). Além disso, passavam aqui pelos perigos da carne e do coração, o que era intensamente preocupante para a salvação de suas almas, alicerce de vida no século XVI.

OS MENinos órfãos e A MisSÃo: enCONTRO E DESENCONTRO DE CULTURAS

Em Salvador, os meninos órfãos vindos do Reino juntaram-se aos meninos filhos da terra e, também, aos meninos mestiços, no "colégio" construído próximo da Sé, no terreiro de Jesus, e que recebeu o nome de Colégio dos Meninos de Jesus. Em 1552, escreveu Nóbrega (1988, p. 129), sobre o Colégio dos Meninos de Jesus e o trabalho dos meninos órfãos, que "vai em muito crescimento, e fazem muito fructo, 
porque andam pelas aldeias com pregações e cantigas de Nosso Senhor pela língua que muito alvoroça a todos [...]”.

De meninos recolhidos para serem educados na fé e na moral cristãs, transformaram-se em obreiros junto dos padres. Na escola, em contato com meninos mestiços, que sabiam o português do pai e o tupi da mãe (FERREIRAJR.; BITTAR, 2004), e com os meninos índios que estavam sendo alfabetizados em português pelos padres e aprendendo a doutrina cristã, os órfãos aprendiam a língua mais falada na costa do Brasil, o tupi; assimilavam também a cultura indígena, pois circulavam, cantando na língua dos índios, dançando e tocando instrumentos indígenas nas aldeias e nos aldeamentos. Escreve Nóbrega (1988, p. 115) sobre os meninos órfãos em 1551: "os meninos órfãos, que nos mandaram de Lisboa, com seus cantares atraem os filhos dos Gentios e edificam muito os Christãos".

$\mathrm{Na}$ carta dos meninos órfãos, de agosto de 1552, escrita pelo padre Francisco Pires ao padre Pedro Domenech, que estava em Lisboa, há importante descrição do que passavam e praticavam os meninos órfãos no Brasil. Peregrinações pelas matas e pelas aldeias indígenas, pregando em língua da terra os ensinamentos da vida cristã, para jovens e adultos, falando da morte, do inferno, do diabo, sendo recebidos em algumas aldeias como santos, "los niños, entretanto que ay estuvieron, fueron bien acogidos e les barrieron las calles como a santos" (LEITE, 1954a, p. 380). Desse modo, os nativos recebiam, segundo seus costumes, os caraíbas e pajés (HERNANDES; FARIA, 2013), preparando os caminhos para esses seres adorados pelos indígenas entrarem nas tabas. Por outras aldeias, eram tidos como demônios: em algumas ocas, "porque no fuésemos a ellas, hacían fuego y quemaban sal y pimienta, porque con la fortaleza y hedor no pasásemos" (LEITE, 1954a, p. 379). Fogo, sal e pimenta eram a maneira de espantar os maus espíritos. No entanto, segundo o missivista, os meninos iam mesmo assim, com a cruz levantada, para dentro das casas dos atemorizados indígenas.

Os meninos órfãos encantavam a todos nas aldeias e nos aldeamentos, misturando aspectos da cultura indígena e da cristã. Em uma aldeia, próxima de Salvador, de índios que recebiam os padres,

[...] os niños cantaron y holgaran mucho, y de noche se levantaron al modo de ellos y cantaran y tañeron con tacuaras, que son unas cañas grossas que dan el suelo y con el son que hazen cantando, y con maracás, que son de unas frutas unos cascos como cocos y aguierados con unos palos por donde dan y pedrezuelas dentro con lo qual tañen. $Y$ 
logo los niños cantando, de noche (como es costumbre de los negros), se levantaban de sus redes e andavan espantados en pos de nosotros. (LEITE, 1954a, p. 383)

Segundo o padre Francisco Pires, os "niños tienen muchos sermones estudiados y tañen e cantan al modo dellos”, e os índios folgavam em ouvi-los. Quando os meninos portugueses iam cantando e tocando no mesmo tom dos índios e com instrumentos indígenas pelas aldeias, "vienen los viejos (que suelen aver miedo de nosotros)" e até as velhas, conselheiras de velhos e moços, "a bailar sin descansar" (LEITE, 1954a, p. 385). Também nas aldeias os meninos índios andavam atrás dos padres e dos meninos portugueses, querendo aprender a cantar e a tocar. Conta ainda que, na festa do Anjo Custódio, foram os meninos pelas aldeias com uma cruz pintada de "pluma de la tierra muy hermosa, con el Niño Jesú em lo alto de la cruz em trage angélico com uma espada (tacape) pequeña em la mano".

Nesse encontro dos pequenos mártires vindos de Portugal com a cultura das selvas brasileiras, nas descrições dos padres, a incorporação de elementos da cultura nativa para o ensinamento da religião cristã, mestiçagem cultural (TODOROV, 2010) que não agradava ao Bispo Dom Pedro Fernandes Sardinha (LEITE, 1954a, p. 407), abria as "portas" das aldeias para os meninos, que traziam consigo os padres. Tanto o padre missivista como o padre Nóbrega estavam certos de que o melhor a fazer para realizar a missão junto aos índios e torná-los cristãos era aproveitar esse encantamento que provocavam os meninos entre eles, espalhá-los por todas as casas da Companhia de Jesus e, assim, levá-los pelas aldeias e pelos aldeamentos.

No entanto, é preciso perguntar: percebiam os padres o que significava para os índios a entrada dos meninos vindos do Reino cantando, dançando, falando sobre Tupã e tangendo o maracá? O maracá era um importante instrumento na crença dos índios, algo como um oráculo, como confirma certa anedota do padre jesuíta Jerônimo, dos anos de 1605 e 1607, numa missão entre os carijós: "Aqui tinha um índio cristão uns dous ou três maracás, mui guardados, que eram de muitos anos, em que parece lhes falava o demônio, os quais, havendo-os o Padre á mão, seu dono vinha depois perguntar o que lhe falaram os maracás. Mas eles, sem falarem, foram ao fogo" (LEITE, 1940, p. 240).

No discurso do padre Francisco, contaminado por sua formação cristã, católica e, sobretudo, jesuítica, os índios cantavam e dançavam ao som dos maracás e das taquaras, seguindo os meninos órfãos, porque tinham se convertido ao cristianismo, iluminados que foram por Deus. No entanto, pode ser que os índios simplesmente 
seguissem cantando e dançando com os meninos por acreditarem que os meninos órfãos estivessem aderindo a sua cultura e religião. Pode ser também que esses índios de uma aldeia híbrida - parte aldeia, parte confinamento cristão - estivessem misturando aspectos de sua cultura com a cultura estrangeira, mestiçagem cultural.

Certo é que os meninos órfãos vindos do Reino, onde haviam sido retirados das ruas da Ribeira e recolhidos em um Colégio aos cuidados espirituais e materiais dos padres jesuítas, na América Portuguesa circulavam por todos os lugares em que andavam os padres e viviam a difícil realidade da vida nas matas e no mar. Em 1553, segundo carta de Brás Lourenço, de março de 1554, encontramos os "niños Y los demás que allí estábamos, asi de los niños como Hermanos nos embarcamos algunos 140 15" (LEITE, 1954b, p. 40) na embarcação que levaria boa parte dos padres e dos irmãos da Companhia de Salvador para São Vicente, lugar que Nóbrega considerava melhor para a evangelização dos índios. No mesmo barco estava o irmão José de Anchieta, recém-chegado ao Brasil. Esse barco naufragaria próximo de Abrolhos e, após acreditarem os navegantes que todos iriam morrer no mar, foram salvos pelos índios.

Y por La mañana nos venimos para La tierra con una vela que ordenaran, $y$ venimos por gracia de N. Señor a un Rio que llaman de las Caravelas. Llegando allí quiso N Señor que estaban aquellos negros de paz entonces. Vinieron ellos con almadias de cáscara de palo y llevárannos para su Aldea, y hiziéronnos fuego porque íbamos mui mojados, $\mathrm{Y}$ allí estuvimos algunos 8 o 9 días pasando mucha hambre, que no avia que comer, porque esos negros no hacen ningún bien sino a quien se lo paga. Entonces pedimos a la gente del navío algún rescate de limosna y comprábamos para comer. Cuando no teníamos que comer, que era lo más del tiempo, comíamos de las calabaças de los negros cocidas sin sal e sin aceite, con harina podrida y cosíamoslas y comíamoslas en los alguidares y ollas en que ellos cosen y comen la carne humana. A las vezes me venia asco, mas el hambre lo quitava (LEITE, 1954b, p. 44).

Grande parte dos nativos da América Portuguesa era constituída de índios antropófagos, o que causou um difícil embate de culturas, sobretudo com os padres, que os consideravam bárbaros e, por vezes, inumanos, o que, para alguns deles, impossibilitaria a missão, pois não seriam iluminados pela Graça. Nóbrega escreveu o "Diálogo para Conversão do Gentio", que provou, segundo a definição escolástica sobre a alma humana, que os índios eram humanos. Afinal, tinham inteligência, 
memória e vontade, e seus maus costumes eram, na verdade, porque o demônio havia se apoderado de suas almas pelos erros de seus avós (NÓBREGA, 1988). Para os índios, esse embate de culturas não deve ter sido fácil também, pois a antropofagia era parte central de sua religião, de suas crenças e foi combatida sem tréguas pelos padres, ajudados nisso pelo governo.

Continua sua descrição o padre:

De dia nos ívamos por esses matos a comer frutas silvestres, que llaman mangabas, que son como sorvas de Portogal; otra que lhaman yba putangat, que son como moras de silvas y tenen el mismo sabor, $y$ en esto nos manteníamos. $Y$ ansi también se pusieron los niños a cantar algunas cantigas de aquí hizieron en lengua de los negros y otras en la nuestra. (LEITE, 1954b, p. 44).

Os meninos cantavam e encantavam a todos. Contudo, revelou o padre missivista, quando pedia a um deles língua para falar de Deus, aproveitando-se da audiência, e o menino passava a falar da morte, atemorizavam-se os índios que pediam para que parasse de falar: "mas como vino a hablar de la muerte no quisieron oír, y dizian a la lengua que no hablase más, que ya hecho era, que cantasen” (LEITE, 1954b, p. 44). Os nativos não queriam ouvir sobre a morte e diziam, segundo o padre Braz Lourenço: "Taxemoraíumé, que quiere dizir no me venga mal, porque pensam que le podíanmos dar salud e desta manera vivíamos” (p. 44). A guerra entre tribos inimigas, a vingança, era forma primaz de organização da vida nas selvas, segundo Fernandes (1963). O morto, nem tanto a morte, atemorizava os nativos do Novo Mundo, segundo Clastres (1995), pois acreditavam que a alma daqueles que não cumpriram com valentia suas funções de guerreiros encarnavam em animais ferozes, como o jaguar, a cobra, o morcego, entre outras feras, que os perseguiam nas matas. (HERNANDES, 2010).

\section{Meninos órfãos QUe Se tornaram SaCerdotes participam de UMA FESTA: MESTIÇAGEM CULTURAL}

Em 1556, o Colégio dos Meninos de Jesus, que recebia e mantinha os meninos órfãos vindos do Reino, foi transformado em Colégio Canônico, não podendo mais recebê-los e mantê-los. Nóbrega abrigou, com a ajuda do governador Mem de Sá, alguns desses meninos em casas próximas ao colégio. Ali viviam, faziam suas refeições e eram educados na doutrina cristã. Em uma relação de padres e irmãos 
jesuítas no Brasil, de 1568 (LEITE, 1960, p. 477), tem-se notícia de alguns "niños huerfanos" que se tornaram "muy útiles operários (sacerdotes)", como "Symeon Gonçales, Antônio de Pina e Joan Perera”. Sacerdotes que desde cedo viveram com os índios, misturados entre duas culturas. Eis a descrição de uma festa religiosa no aldeamento do Espírito Santo de que participaram:

Estando já quase toda la gente junta y todo a punto pera se començar las vísperas de pontificial, dan nos rebate como venian todos los niños de las otras problaciones em procession; y, saliendo, divisamos a longe ser el Pe Antonio Rodriguez, el Pe Simeon Gonçalvez, el Pe Antonio de Pina y el Pe Baltezar Álvarez, los quales com toda la gente de sus aldeas venian a ganhar jubileo. Tratan quatro cruzes, las quales seguian gran multitud de niños. Venian todos, como tienen de custume, co sus devisas de galenteria, unos com sus grinaldas en las cabeças y palmas en las manos, otros con diademas hechas de plumas de diversas colores a su modo hermosas y lustrosas, otros com grandes ramales de cuentas brancas al pescueço, finalmente cada uno llevava aquello que a los oyos de todos pareceisse más gallano y polido. (LEITE, 1960, p. 75).

Com o fim da procissão vinham os padres e seus discípulos, cantando as "letanias”. Aqueles que vieram até a aldeia do Espírito Santo ganhar o jubileu, vendo a procissão chegar por aqueles vales, se alvoroçaram, não se cansando de dar mil louvores e graças ao senhor por aquele espetáculo devoto. Quando os que vieram seguindo a procissão entraram na igreja, sobretudo os meninos galantes, ninguém conseguiu reter as lágrimas. O que mais alegrava a todos era ver "a los hijos destos, que era una gran muchedumbre de indiozicos todos christianos, muy bien doctrinados en la fee" (LEITE, 1960, p. 75).

Na hermenêutica que se faz da carta do padre Blasques, descrevendo esse evento na grande aldeia do Espírito Santo, os meninos índios dessa aldeia, como aqueles que vieram em procissão de outros aldeamentos, foram assimilados pela religião cristã, segundo a interpretação do padre sobre a participação dos "indiozicos todos christianos” (LEITE, 1960, p. 75) na procissão, e promoveram um espetáculo devoto que levou todos às lágrimas.

A interpretação sobre essa aptidão que os índios teriam para a assimilação à religião cristã, que se acreditava universal e que via os outros, os índios, como seres com "alma selvagem ou mesmo sem alma naturalmente subordináveis às instituições" (HANSEN, 1998, p. 351), "páginas em branco" (TODOROV, 2010, p. 49), prontos e 
preparados para receber a "verdadeira fé", teve início, segundo Coli (1988), no encontro de nativos e estrangeiros na primeira missa realizada no Brasil. Na carta de Pero Vaz de Caminha sobre a participação dos nativos na primeira missa no Brasil, pareceu ao escrivão da frota de Cabral que os homens do novo mundo estavam ajoelhando-se e levando as mãos para o céu como faziam os cristãos, interpretação que levou Gabriel Soares de Souza, comerciante e cronista da época, a afirmar que a participação dos índios na primeira missa demonstrava a afirmação de Dom Manuel, rei de Portugal, e da religião cristã sobre aqueles povos. Essa interpretação foi questionada ao longo do tempo, mas principalmente no século XIX. Segundo Coli (1998, p. 119), no século XIX, os protestantes Shoutey e Varnhagen desconfiaram da vocação dos índios na primeira missa, descrita por Caminha, supondo que os índios, ao ficarem de joelhos quando os portugueses se ajoelhavam e ao levantarem as mãos para o céu, quando os estrangeiros levantavam, poderiam estar apenas realizando um ato mecânico de imitação ou espanto, e não de devoção. Isso não deixa de ser, também, suposição, já que não se tem a voz dos índios sobre o assunto.

\section{CONSIDERAÇões Finais}

Neste artigo, têm-se os ditos e os escritos dos padres e, obviamente, o modo como interpretaram o que viram, o que viviam, sobretudo o que desejavam ver e viver. Interpretações contaminadas por suas crenças, por sua formação de jesuítas, mártires cristãos empunhando o estandarte da Cruz e saindo à luta contra os povos idólatras, hereges, disformes, como eram considerados os índios, pela única e verdadeira fé. Os olhos dos padres não viam esse outro cultural que habitava as selvas apenas como seres diferentes deles, mas como seres disformes, sem memória de Deus, que era preciso "rememorizar por meio da palavra divina ainda que em tupi" (HANSEN, 2005, p. 21).

Nas imagens construídas nas descrições dos padres Domenech e Francisco, inscritas nas cartas, "os pequenos mártires" empunharam a Cruz de Cristo para subir ao batel, seguindo viagem pelo tenebroso Atlântico, para lutar pela fé cristã e católica, semelhante ao que fizeram os mártires da Igreja. No Brasil, invadiram as aldeias com a Cruz levantada, formosamente pintada com plumas da terra, "cantando tangendo ao modo dellos" (Leite, 1954, p. 384), usando instrumentos de rituais religiosos indígenas de morte de contrários, também quando estavam bêbados (LEITE, 1954a, p. 407), "para les predicaremos la verdade del mismo Dios execitada en nuestras almas” (p. 407), para converter todo o Brasil. Intrometeram-se na vida dos índios, 
ou seja, "imiscuíram-se" no "mundano", na tentativa de transformá-lo em sagrado (FERNANDES, 2008, p. 181), sem se importar que canto, música e instrumentos como o maracá, que usavam para atrair os índios, fizessem parte do "culto religioso" deles (BOSI, 1992, p. 12), segundo esclarece o padre Francisco ao Padre Domenech: "Los negros a sus contrários (a los quales quieren muy mal tanto que se comem unos a otros) los dexan entrar en sus tierras y casas, si les traen tañeres y cantares, y assi los nombran santidades y les dan quanto tienen” (p. 12). Se os índios deixavam entrar em suas aldeias essas santidades, os demônios, seus padres, que contavam mentiras e falsidades, que tanto agradavam os índios, o que acontecerá, pergunta Francisco, quando os meninos entrarem nas aldeias com sua música e pregando a verdade de Deus? Ele mesmo responde: "farão tremer os demônios e seus poderes ficarão como nublados ante o sol” (LEITE, 1954a, p. 384). O padre cronista da carta dos meninos e, segundo ele, também o padre Nóbrega acreditavam que bastava introduzir nos rituais indígenas os valores cristãos para afastá-los dos demônios, os caraíbas e pajés, de suas crenças ancestrais e trazê-los para a comunidade da Igreja.

A constituição da escrita dessa história (CERTEAU, 2002) teve como recurso os discursos dos padres sobre sua missão, sobre os índios, relatados em cartas - as cartas jesuíticas. Esses discursos seguem uma determinada ordem, um olhar contaminado por outros discursos, por outras verdades, que revelam o que e como eles percebiam sua missão; como construíram a imagem do indígena, dos meninos órfãos vindos do Reino para cá, do enfrentamento de culturas, dos encontros e desencontros da cultura europeia com a cultura nativa - relato, descrição e interpretação que fizeram para seus companheiros de Companhia no século XVI. Assim, a história do enfrentamento de culturas, que teve lugar na mata selvagem do Brasil do século XVI, com meninos órfãos vindos do Reino como personagens centrais, traz nas suas linhas e entrelinhas apenas a hermenêutica do olhar, da interpretação, da descrição dos padres para esses encontros e desencontros de culturas. Foi a partir desses ditos e escritos que se fez a hermenêutica deste estudo.

\section{REFERÊNCIAS}

BITTAR, M. O estado da arte em história da educação brasileira após 1985: um campo em disputa. In: LOMBARDI, J. C.; SAVIANI, D.; NASCIMENTO, M. I. M. (Org.). Navegando pela história da educação. Campinas: HISTEDBR, 2006. p. 1-24. Disponível em: <http://www.histedbr.fae. unicamp.br/navegando/index.html>. Acesso em: set. 2015. 
Meninos órfãos vindos do Reino para a América Portuguesa: mestiçagem cultural

BOSI, A. Dialética da colonização. São Paulo: Companhia das Letras, 1992.

CERTEAU, M. A escrita da história. Tradução de Maria de Lourdes Menezes. $2^{\mathrm{a}}$ ed. Rio de Janeiro: Forense Universitária, 2002.

CLASTRES, P. Crônica dos índios guayaki. Tradução de Tânia Stolze Lima e Janice Caiafa. Rio de Janeiro: Editora 34, 1995.

COLI, J. A primeira missa e invenção da descoberta. In: NOVAES, A. (Org.) A descoberta do homem e do mundo. São Paulo: Companhia das Letras, 1998.

CONSTITUIÇÕES da Companhia de Jesus e normas complementares. São Paulo: Loyola, 1997.

FAVACHO, A. O recolhimento dos meninos. Por uma genealogia da ordem pedagógica brasileira. Tese (Doutorado) - Universidade de São Paulo, São Paulo, 2008.

FERNANDES, E. F. Fernão Cardim: a epistologia jesuítica e a construção do outro. Revista Tempo, Rio de Janeiro, RJ, v. 27, p. 176-198, 2008. Disponível em: <http://www.scielo.br>. Acesso em: jan. 2015. FERNANDES, F. A organização social dos tupinambá. São Paulo: Instituto Progresso Editorial, 1963. FERREIRA JÚNIOR, A.; BITTAR, M. Pluralidade lingüística, escola de bê-a-bá e teatro jesuítico no Brasil do século XVI. Educação e Sociedade, v. 25, n. 86, p. 472-482, 2004.

HANSEN, J. A servidão natural do selvagem e a guerra justa contra o bárbaro. In: NOVAES, A. Descoberta do homem e do mundo São Paulo: Companhia das Letras, 1998. p. 347-373.

. A escrita da conversão. In: COSTIGAN, L. H. Diálogos da conversão. Campinas: Editora da Unicamp, 2005. p. 15-43.

HERNANDES, P. R. A Companhia de Jesus no século XVI e o Brasil. Revista HISTEDBR On-line, v. 40, p. 222-244, 2010.

HERNANDES, P. R.; FARIA, M. R. Teatro jesuíta na América Portuguesa. Leitura: Teoria \& Prática, V. 31, p. 61-79, 2013.

LEITE, S. S. J. Novas cartas jesuíticas. De Nóbrega a Vieira. São Paulo: Companhia Editora Nacional, 1940. . Cartas dos primeiros jesuítas do Brasil - 1538-1553. v. 1. São Paulo: Comissão do IV Centenário da Cidade de São Paulo, 1954a.

. Cartas dos primeiros jesuitas do Brasil - 1553-1558. v. 2. São Paulo: Comissão do IV Centenário da Cidade de São Paulo, 1954b. . Monumenta Brasiliae - 1563-1568. Coimbra: Tipografia da Atlântica, 1960.

MARCÍlIO, M. L. História social da criança abandonada. $2^{a}$ ed. São Paulo: Hucitec, 2006.

NÓBREGA, M. Cartas jesuíticas 1. Belo Horizonte: Itatiaia; São Paulo: Editora Universidade de São Paulo, 1988.

RAMOS, F. P. A história trágico-marítima das crianças nas embarcações portuguesas do século XVI. In: PRIORI, M. (Org.). História das crianças no Brasil. $6^{\mathrm{a}}$ ed. São Paulo: Contexto, 2008. p. 19-54. TODOROV, T. A conquista da América: a questão do outro. Tradução de Beatriz Perrone-Moisés. $4^{\mathrm{a}}$ ed. São Paulo: WMF Martins Fontes, 2010. 
SOBRE O AUTOR

Paulo Romualdo Hernandes tem Graduação e Licenciatura em Filosofia pela Pontifícia Universidade Católica de Campinas, é Mestre e Doutor em Educação pela Universidade Estadual de Campinas (UNICAMP). É autor do livro O Teatro de Anchieta. Arte e Pedagogia no Brasil Colônia, com apoio da FAPESP.É docente e membro permanente do Programa de Pós-Graduação em História Ibérica e em Educação da Universidade Federal de Alfenas (UNIFAL-MG).

E-mail: paulorh_mancini@hotmail.com

Recebido em 19 de maio de 2015 e aprovado em 05 de novembro de 2015. 